\title{
Ethical dilemmas for the areas of Nursing and Health in relation to Preprints
}

\begin{abstract}
Dulce Aparecida Barbosa', Maria Itayra Padilha"
'Associate Professor and Livre Docente of the Medical Surgical Nursing Department of the Nursing School at Universidade Federal de São Paulo. Director of Communication and Publishing of Brazilian Nursing Association (ABEn). Editor-in-chief at Revista Brasileira de Enfermagem. São Paulo, São Paulo, Brazil. "Full Professor of the Nursing Department of the Universidade Federal de Santa Catarina and the Graduate Program in Nursing. Director of the Research and Study Center of ABEn Nacional, management from 2016 to 2019. Associate Editor of Revista Texto \& Contexto Enfermagem. Florianópolis, Santa Catarina, Brazil.
\end{abstract}

\section{How to cite this article:}

Barbosa DA, Padilha MI. Ethical dilemmas for the areas of Nursing and Health in relation to Preprints. Rev Bras Enferm [Internet]. 2018;71(Suppl 6):2602-3. [Thematic Issue: Good practices in the care process as the centrality of the Nursing] DOI: http://dx.doi.org/10.1590/0034-7167.201871supl601

According to a recent publication by a group of researchers at the National Institutes of Health and the Whitehead Institute ${ }^{(1)}$, a preprint submission is defined as a complete written description of a scientific work that has not yet been published in a journal. It may be a research article, an editorial, a review, or another type of document that is ready to be peer reviewed or being reviewed, or even rejected; but that the authors are willing to make their content public, independent of the final result. In short, preprint is a path to the dissemination of knowledge produced by researchers and has not completed the typical flow of publication, but can be valuable to the community, easily discovered and accessed and cited $^{(1)}$.

In 1991, the area of Physics, and later other disciplines, including Mathematics, Computer Science and Quantitative Biology, began the tradition of making preprints available through the arXiv repository, which currently contains more than 1 million preprints. The availability of preprints in the area of Biomedicine has gained significant attention from the scientific community recently and has led to the formation of a scientist-led effort, ASAPbio, to promote its use. As a result of the ASAPbio meeting, held in February 2016, ten simple rules were pointed out to consider the use of preprint as a communication mechanism ${ }^{(1)}$. They are:

Rule 1: Preprints speed up dissemination: The average review time between submitting and posting an article is about 100 days, the preprint is online in 24 hours;

Rule 2: Preprints should be licensed and formatted to facilitate reuse: Authors are encouraged to use licenses and formats that facilitate reuse, while retaining the copyrights of their work. For each version posted a DOI is assigned and the document can be quoted;

Rule 3: Preprints provide a record of priority: All preprints include a timestamp, indicating when the article was submitted, which usually occurs within 24 hours after submission, and anyone using the web search engines can determine the order of priority relative to other works. ArXiv has created a transparent public record of the work of a scientist. Although journals provide an important validation service through peer review, prioritization can be significantly delayed due to the time that the work is not made public during the peer review process and other editorial processes in most journals;

Rule 4: Preprints do not lead to being scooped: Prevents the possibility of "getting ahead", as can happen in non-public review processes, that is, the disclosure of a new discovery is privileged by its publication almost simultaneously; 
Rule 5: Preprints provide access to scholarly content that would otherwise be lost: Results that are valuable to the scientific community, even if they are not innovative enough for publication in the journal;

Rule 6: Preprints do not imply low quality: The peer review process can add significant value to the work, pointing out mistakes or paths to improvement. However, the authors should be following up on their preprint, because it is a public disclosure and therefore a quoted entity, though not peer-reviewed. Even without peer review, other researchers will be reading, evaluating, qualifying and judging the work. The authors' reputation is at stake;

Rule 7: Preprints support the rapid evaluation of controversial results: Such as the publication indicating that the radiation emitted by the cell phone increased cancer rates in animals. Given the controversy surrounding such a claim, the National Institute of Health $(\mathrm{NIH})$ felt the obligation to release all data, including internal reviews, as soon as possible so that others could review the findings and assess the truth of the findings;

Rule 8: Preprints do not typically preclude publication: Very few journals consider preprints as a "prior form of publication" and reject such manuscripts on the grounds that they were sent to a preprints server without prior evaluation. However, in recent months, life science journals are developing preprint-friendly policies for publishers to appreciate the value of preprints as a contribution that can help the author improve his work and manuscript, leading to better publication;

Rule 9: Preprints can further inform grant review and academic advancement: The availability of preprint provides the reviewer of development agencies with the evidence they need to substantiate scientific research;

Rule 10: Preprints - one shoe does not fit all: BioRxiv, the fastest growing preprint repository for the life sciences, does not accept preprints that, if posted, can have a detrimental effect on human health because preprints in this repository only undergo a superficial human review before to be posted. There is a possibility that potentially harmful information (e.g, unverified claims about the side effects of vaccines, etc.) or maybe personal and private information may be revealed. This has ethical, legal and social (ELSI) and intellectual property (IP) issues ${ }^{(1)}$.

Added to this scenario, preprints are still considered as gray or gray literature, that is, they are of sufficient quality to be collected and preserved by libraries, but not controlled by publishers, due to their immediate publication and not previously peer-reviewed ${ }^{(2)}$.

These ten rules point to the positivity of the preprint and, in a sense, meet what Peter Demo advocates in terms of intersubjectivity in the production of knowledge, that is, put himself to the criticism of his peers immediately and without intermediation of other evaluators.

We see intersubjective, intense, and freely communicated work in which researchers control each other within naturally debatable parameters. Since it is not possible to establish anything peremptory, the intersubjective relation must be democratic, so that the authority of the argument can prevail ${ }^{(3)}$.

Through this innovation in the presentation of scientific knowledge, the sciences in the areas of Health and Nursing face an ethical dilemma because of its production since the beginning, supported by the pillars of the Helsinki Declaration, Fapesp's Good Practices in Research and SciELO, knowledge gained at national and international events on research integrity and the canonical process of peer review.

The question is: Is it a new way of disseminating knowledge? Does this shoe fit us?

\section{REFERENCES}

1. Bourne PE, Polka JK, Vale RD, Kiley R. Ten simple rules to consider regarding preprint submission. PLoS Comput Biol[Internet]. 2017[cited 2018 Aug 26];13(5):e1005473. Available from: https://doi.org/10.1371/journal.pcbi.1005473

2. Dorris CS. Grey Literature in Health Science: what is Gray/Grey Literature [Internet]. 2018[cited 2018 Aug 26]. Available from: http://guides.dml.georgetown.edu/greylit

3. Demo P. Cuidado Metodológico: signo crucial da qualidade. Soc Estado[Internet]. 2002[cited 2018 Aug 26];17(2):349-73. Available from: http://www.scielo.br/pdf/se/v17n2/v17n2a07.pdf 